\title{
25 лет официальному представительству LECO Corporation в России и странах СНГ
}

Рассказывает директор по продажам ЗАО «ЛЕКО ЦЕНТР-М» Дмитрий Борисович Чиркин

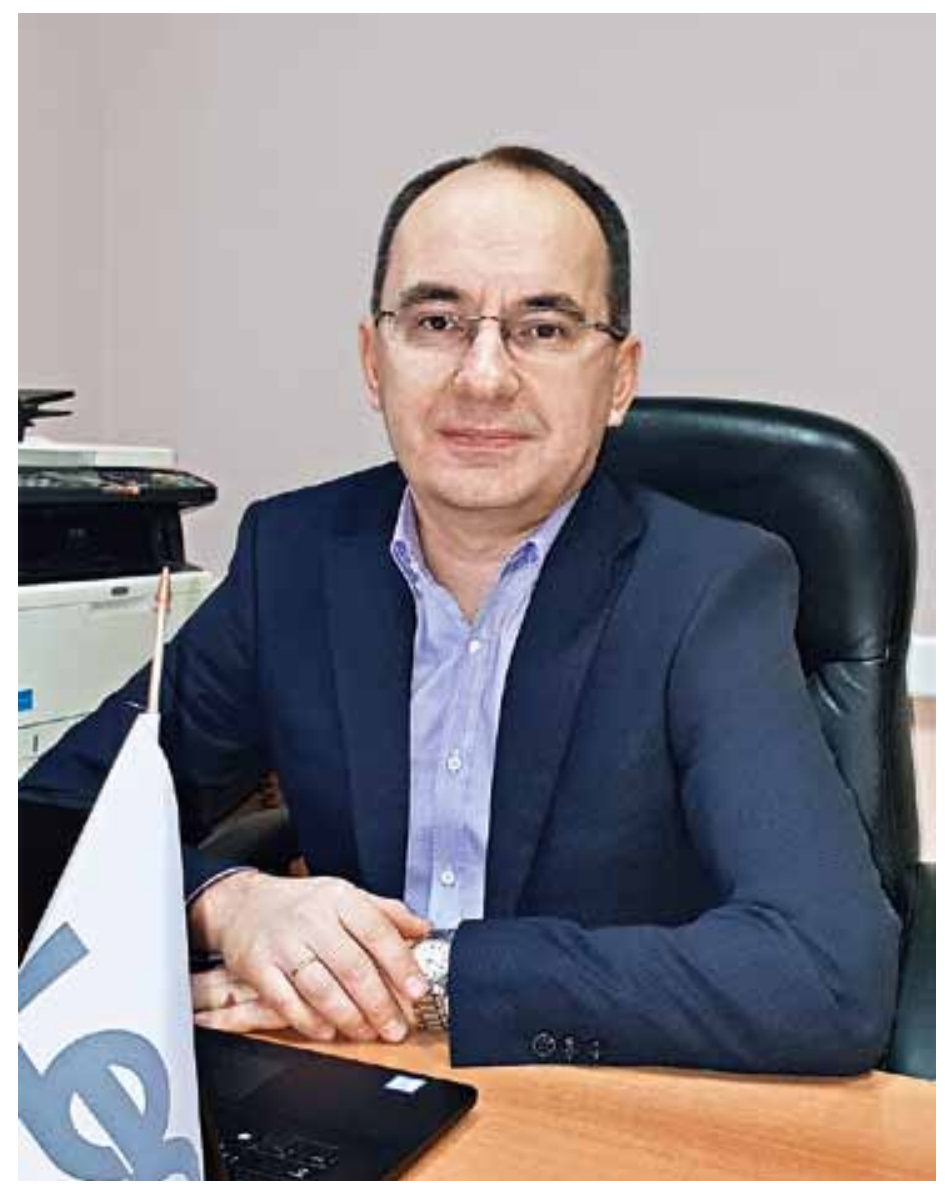

Корпорация LECO известна во всем мире как производитель широкого спектра высокотехнологичного аналитического оборудования для различных отраслей производства и исследовательской деятельности. Продукция компании всегда отвечала растущим потребностям современного общества. Первые приборы - анализаторы различных элементов - предназначались для работы на предприятиях тяжелой промышленности, сегодня LECO предлагает ряд инновационных решений, идеально подходящих для исследований в области фармацевтики, метаболомики, криминалистики, токсикологии, анализа ароматов и др. методами хроматографии и масс-спектрометрии. Четверть века на российском рынке активно и плодотворно работает представительство корпорации LECO. Об истории компании, особенностях оборудования, а также успехах и перспективах работы мы расспросили директора по продажам ЗАО «ЛЕКО ЦЕНТР-М» Дмитрия Борисовича Чиркина. 
Расскажите, пожалуйста, о вашей компании. Как давно она работает на рынке?

История компании LECO берет свое начало с 1936 года, когда ее специалисты разработали и представили уникальный для своего времени анализатор для быстрого определения углерода в металлах. В дальнейшем ассортимент выпускаемого оборудования постоянно расширялся. Сегодня компания производит анализаторы серы, азота, кислорода, водорода, оптико-эмиссионные спектрометры тлеющего разряда, приборы для анализа органических материалов (элементные анализаторы, калориметры, термогравиметрические анализаторы), а также оборудование для металлографии и пробоподготовки и др. Надежность и отличные метрологические характеристики сделали элементные анализаторы LECO де-факто стандартом качества для определения газообразующих примесей в лабораториях большинства крупнейших университетов, научных институтов, металлургических, машиностроительных предприятиях всего мира.

За более чем 80-летнюю историю компания открыла более 30 представительств с широкой сетью дистрибьюторов по всему миру, в том числе и в России. Первые поставки оборудования LECO в начале 70-х годов прошлого столетия были осуществлены на крупные предприятия СССР, такие как Магнитогорский металлургический комбинат, Норильский горно-металлургический комбинат и др. Убедившись в высоком качестве продукции LECO, Министерства черной и цветной металлургии стали ее централизованно закупать. С тех пор сменилось уже несколько поколений приборов, но у наших заказчиков в России до сих пор в эксплуатации находятся десятки единиц оборудования, установленного еще в 80-х годах прошлого столетия, что лучше всяких слов подтверждает его высокое качество и уровень нашей сервисной поддержки.

Официальное представительство LECO в России (ЗАО "ЛЕКО ЦЕНТР-М») бЫЛО ОТкрЫТО в 1994 ГОДУ. Основная сфера деятельности - поставка и сервисное обслуживание оборудования LECO. Всего у наших заказчиков в России установлено более 1200 единиц оборудования LECO. С июня 2004 года в офисе Московского представительства LECO работает демонстрационная лаборатория, в которой представлено самое современное оборудование для анализа органических материалов. В Институте металлургии и материаловедения им. А. А. Байкова РАН с 1999 года действуют научный центр и демонстрационная лаборатория с оборудованием LECO для металлургической отрасли.

\section{Какое оборудование производит компания LECO?}

Спектр выпускаемого компанией LECO оборудования достаточно широк. Для металлургических и машиностроительных предприятий наша компания производит элементные анализаторы для определения содержания углерода, серы, азота, кислорода, водорода, оптико-эмиссионные спектрометры тлеющего разряда, оборудование для металлографии и пробоподготовки. На угледобывающие предприятия и коксохимпроизводства металлургических комбинатов мы поставляем приборы для определения серы, углерода в коксе и угле, термогравиметрические анализаторы для определения содержания влаги, летучих веществ и зольности, автоматические калориметры для определения теплотворной способности твердых и жидких топлив, а также анализаторы плавкости золы. Все оборудование LECO внесено в Государственный реестр средств измерений РФ, анализы выполняются в полном соответствии с российскими и международными стандартами.

\section{Гиавные преимущества оборудования LECO - уникальность и надежность}

ЗАО "ЛЕКО ЦЕНТР-М" яВляется также эКСКлюзИвным представителем в России компании RB, которая производит испытательное оборудование для контроля качества угля, кокса (дилатометры, пластометры, установки для определения показателей CRI / CSR) и железорудного сырья (определение прочности окатышей, восстановления руд под нагрузкой и многих других параметров) в полном соответствии со стандартами ASTM и ISO.

\section{В чем основные преимущества вашей продукции?}

Прежде всего, ключевыми преимуществами являются высокая надежность, доказанная десятилетиями успешной эксплуатации приборов на предприятиях РФ, а также инновационные решения, реализованные при разработке и производстве анализаторов. Компания LECO с момента своего основания придерживается политики разработки и производства своими силами большинства наиболее критичных узлов, таких как печи, детекторы, платы. Мы не приобретаем у других компаний разнообразные комплектующие, которые имеют свои достоинства и недостатки и требуют адаптации для их применения в аналитическом оборудовании, а используем узлы собственного производства. При разработке учитывается опыт эксплуатации анализаторов предыдущих поколений и применяются самые передовые технологии. Например, благодаря использованию в анализаторах LECO CS744 индивидуально термостатируемых ИК-ячеек нового поколения без движущихся частей, с помощью двух ячеек: одна - на углерод, другая - на серу перекрывается весь диапазон измерения от единиц ppm до нескольких процентов, что обеспечивает оди- 
наково высокую точность во всем интервале концентраций. У большинства других производителей анализаторов серы, углерода в приборах устанавливается по две ячейки на каждый элемент, при этом при высоких концентрациях абсолютная погрешность существенно выше, чем при низких содержаниях.

Второй пример - уникальный анализатор для одновременного определения азота, кислорода, водорода LECO ONH836. который обеспечивает подтвержденный нижний предел определения азота, кислорода, равный 0,05 ppm. Именно подтвержденная возможность детектирования минимальных концентраций лучше любых рекламных обещаний говорит об уровне технических решений, которые реализованы при производстве определенного типа аналитического оборудования. Кроме того, в анализаторе ONH836 установлен динамический компенсатор потока, позволяющий определять с высокой точностью низкие содержания азота в титановых сплавах при высоких концентрациях кислорода. Большинство крупнейших производителей и потребителей титана для определения азота и кислорода применяют анализаторы LECO.

\section{Расскажите, пожалуйста, о других уникальных приборах, выпускаемых компанией LECO.}

Наша компания выпускает несколько уникальных "нишевых» приборов. Например, анализатор водорода LECO DH6O3 для определения диффузионно-подвижного, остаточного и общего водорода в пробах, взятых из жидкого металла. Кроме того, с его помощью можно определять содержание диффузионного водорода в сварных швах. Благодаря применению многоразовых кварцевых лодочек, этот прибор

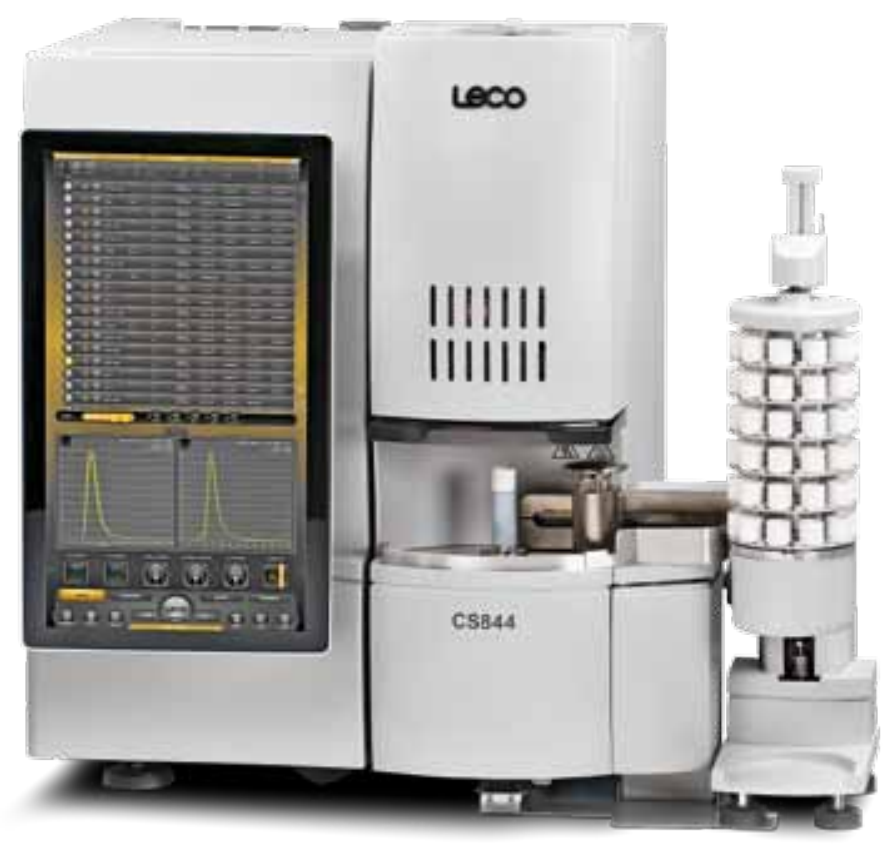

самый экономичный для определения водорода в сплавах на железной основе.

Анализатор LECO RHENG02 с высокой точностью определяет минимальные (от 0,01 ppm) содержания водорода в алюминии и в алюминиевых сплавах. Большинство производителей и потребителей алюминия и его сплавов в России решают эту аналитическую задачу с помощью анализаторов водорода LECO различных поколений.

Большой интерес у аналитиков вызвал новый термогравиметрический анализатор влажности LECO TGM800, который в автоматическом режиме может определять влагу в 16-ти образцах одновременно. При достижении постоянной массы образцов прибор автоматически прекращает анализ, что позволяет с его помощью существенно повысить производительность работы лаборатории. Для объективности приведу следующие цифры. При применении сушильного шкафа или термогравиметрического анализатора на одну пробу среднее время анализа 16-ти образцов составляет (в зависимости от типа образца) 170-200 мин с учетом времени работы лаборанта, тогда как для определения содержания влаги в таком же числе проб на анализаторе LECO TGM800 затрачивается не более 95 мин в автоматическом режиме без участия оператора.

Другой уникальный анализатор LECO RC612 позволяет определить формы углерода (органический, неорганический, элементарный) и воды (поверхностная, кристаллизационная) из одной пробы в ходе одного анализа методом температурного программирования. Много лет определение форм углерода выполнялось методами "мокрой" химии с использованием кислот. В таком методе кроме неудобств, связанных с применением кислот, вводится систематическая ошибка в отношении элементарного углерода. Такая форма углерода всегда ошибочно считается как общий органический углерод. Недавно разработанный стандарт DIN19539 решает эту проблему, предписывая использование температурного программирования для определения общего, неорганического и элементарного углерода. Пользователи анализаторов LECO RC612 могут определять все формы углерода за один анализ без применения кислоты и иных агрессивных реагентов. Этот метод применим для почв, отходов и иных твердых, а также жидких образцов.

\section{Какие еще новинки выпустила на рынок ваша компа- ния?}

За прошедший год наша компания выпустила на рынок пять приборов нового поколения с инновационным По Cornerstone для решения различных задач. Для лабораторий, которые занимаются контролем качества металлов, наибольший интерес представляют новый оптико-эмиссионный спектрометр тлеющего разряда LECO GDS900 и серия шлифовально-полировальных станков LECO PX400, PX500.

Основное преимущество спектрометров тлеющего разряда GDS900 по сравнению с искровыми приборами заклю- 
чается в отсутствии эффекта "памяти" к ранее проанализированным образцам, поэтому можно чередовать анализ сплавов на различной основе без каких-либо дополнительных процедур по чистке штатива, замене электродов и перенастройки спектрометра. Контролируемый процесс катодного распыления образца позволяет анализировать сплавы с низкой температурой плавления, такие как олово, свинец, цинк, припои, баббиты и т.д. Конструкция спектрометра GDS900 предполагает нетермический (механический) характер поступления атомов пробы в разряд, который удобен для одновременного определения трудно- и легковозбудимых элементов, проведения послойного анализа покрытий, минимизирования влияния структуры сплава на результаты исследования. При этом возможно определение точного химического состава литейного, отожженного алюминия, серого, ковкого или белого чугуна и деталей, произведенных методом порошковой металлургии. Размер пятна на объекте после измерения на GDS900 не превышает 4 мм, поэтому легко проводить большое число параллельных измерений на одной пробе и существенно снизить расход дорогостоящих калибровочных образцов и образцов сравнения.

Остановлюсь на некоторых конструктивных особенностях новой серии шлифовально-полировальных станков LECO PX, которая состоит из двух моделей РХ400 и РХ500. В отличие от оборудования других производителей, в станках серии РХ в базовом блоке и в держателе образцов используется привод под прямым углом. Поэтому не нужны приводные ремни, которые обычно со временем растягиваются, а скорость вращения отклоняется от установленной в методе, приводя к необходимости ремонта.

Определенные особенности есть и у диспенсера суспензий. У большинства других производителей диспенсер суспензий представляет собой отдельный громоздкий блок с правой стороны от держателя. От него идет отдельный тракт подачи, нависающий над приводным кругом и препятствующий смене шлифовальных кругов и дисков. В станках РX400 и РX500 тракт подачи интегрирован в держатель образцов, а диспенсер суспензий представляет собой модульную конструкцию в виде отдельных перистальтических насосов. Таким образом, конструкция становится более компактной, и, помимо этого, заказчик сам может выбирать необходимое количество насосов, в зависимости от числа применяемых суспензий. Диспенсеры других производителей обычно поставляются только на пять суспензий, за счет чего стоят дороже. В станкаX LECO серии PX установлен держатель образцов с возможностью центрального и индивидуального нагружения, все параметры процесса настраиваются (скорость вращения приводного круга и держателя образцов, направление вращения держателя образцов, время цикла, расход суспензий и т.д.), и управление осуществляется с большого сенсорного цветного дисплея и русифицированного программного обеспечения.
Как в компании LECO организовано гарантийное и сервисное обслуживание?

Прежде всего, несколько слов о структуре сервисного отдела компании LECO в России, в котором работает в настоящий момент одиннадцать специалистов. Сервисные

\section{Одна из основных тенденций} на аналитическом рынке - растущая
объективность заказчиков при выборе поставщиков

службы LECO находятся в Москве, Екатеринбурге и Кемерово, что позволяет оперативно реагировать на запросы наших заказчиков. 100\% акций ЗАО "ЛЕКО ЦЕНТР-М» принадлежит корпорации LECO, то есть наши многочисленные клиенты в России, по сути, получают гарантийное и сервис-

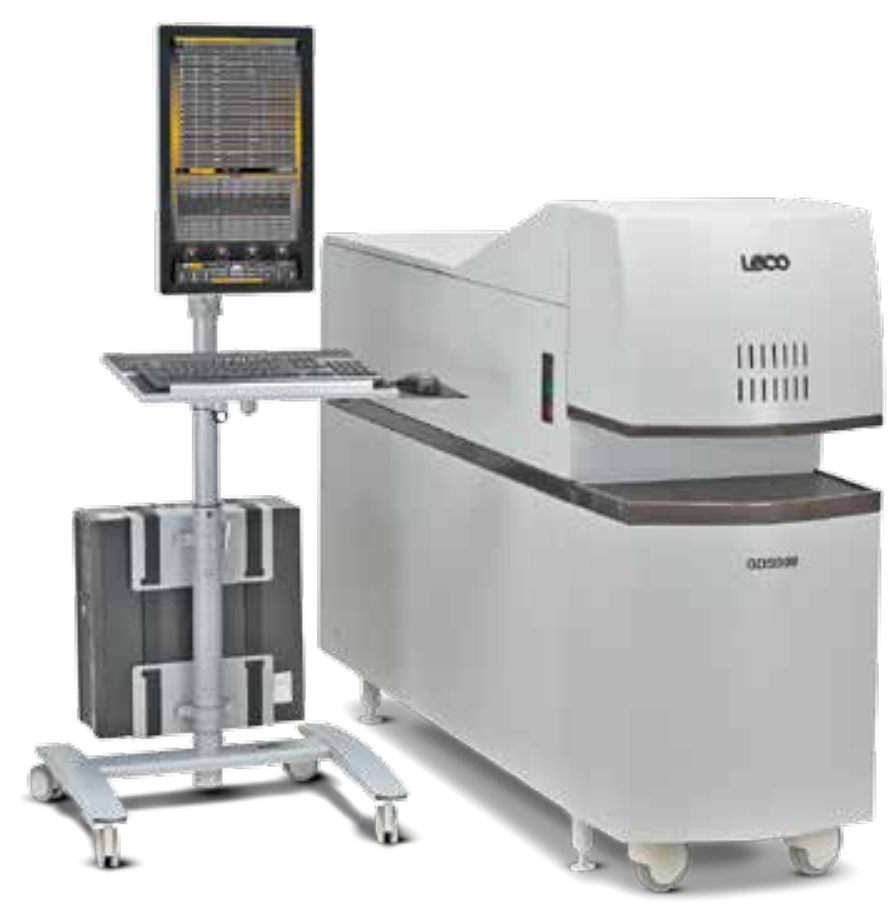

Оптико-эмиссионный спектрометр тлеющего разряда LECO GDS900 


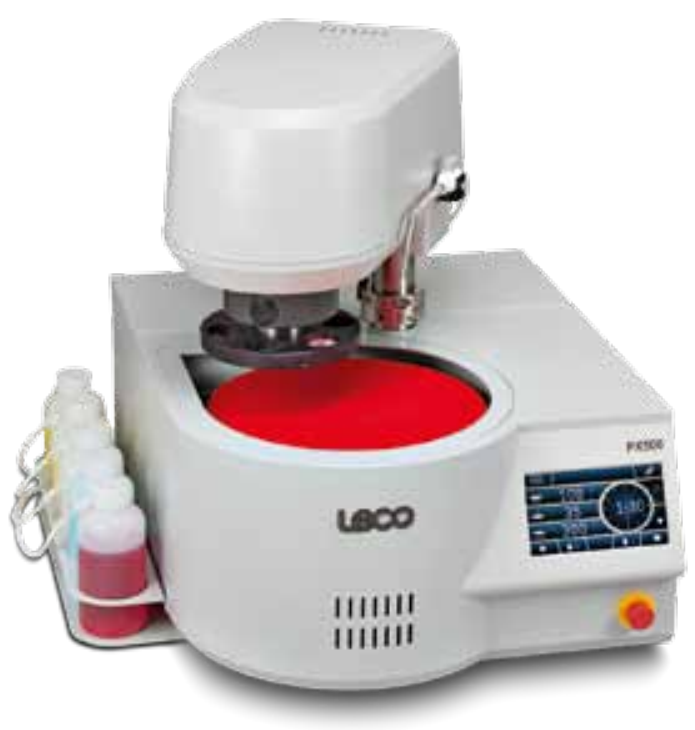

Автоматический щлифовально-полировальный станок LECO PX500

ное обслуживание напрямую от фирмы-производителя. На складах в Москве и Екатеринбурге всегда есть оригинальные расходные материалы и запчасти, и мы гарантируем их быструю поставку в случае необходимости.

\section{Насколько повлияли кризисные явления на вашу деятель- ность? Каковы с вашей точки зрения основные тенденции бизнеса в России?}

В 2018 году мы поставили нашим заказчикам в России почти на треть больше анализаторов, чем годом ранее. Кроме уникальности оборудования LECO и его высокой надежности, росту продаж также способствует наша системная ориентированность на решение различных аналитических задач. Мы не просто поставляем приборы, а предлагаем готовые комплексные решения с применением самого передового оборудования и глубокой методической проработкой.

На мой взгляд, одна из основных тенденций на аналитическом рынке - растущая объективность заказчиков при

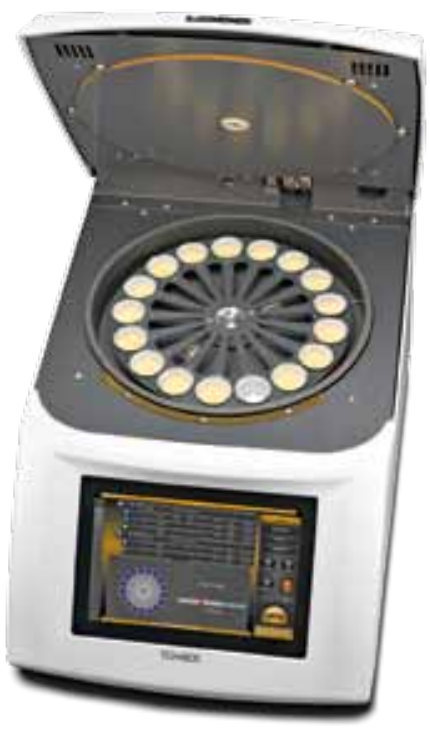

Термогравиметрический анапизатор LECO TGM800

выборе поставщиков. Благодаря Интернету информацию о поставщиках определенного типа оборудования можно собрать за несколько минут. На бумаге все варианты хороши, так как информация приводится с акцентом на особенности оборудования определенного производителя.

Компания LECO на 100\% уверена в возможностях выпускаемого оборудования, его качестве, а также в квалификации своих инженеров. Мы призываем специалистов при выборе оборудования отойти от сравнений цифр и характеристик, приведенных на сайтах и в рекламных брошюрах. Решение следует принимать по результатам анализа реальных проб для объективной оценки возможностей оборудования и компетенций специалистов поставщика. Как показала практика, в большинстве случаев при проведении подобного объективного испытания заказчики делают свой выбор в пользу оборудования LECO.

\section{Спасибо за интересный рассказ.}

С Д. Б. Чиркиным беседовала О. А. Лаврентьева

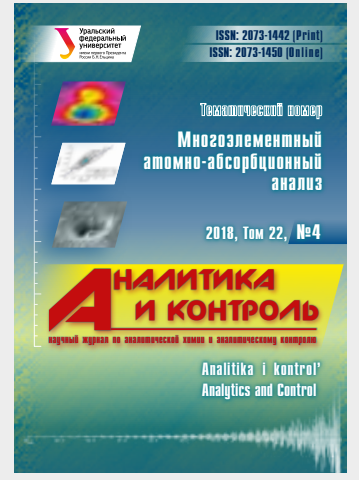

Вышел в свет очередной номер журнала "Аналитика и контроль" 2018, т. 22, № 4

Кацков Д.А.

Введение в многоэлементный атомно-абсорбционный анализ DOI:10.15826/ analitika.2018.22.4.001
Болдова С. С., Лабусов В.А., Кацков Д.А., Селюнин Д. О., Саушкин М. С., Зарубин И.А., Семёнов 3. В.

Атомно-абсорбционный спектрометр "Колибри-ААС" для одновременного многоэлементного анализа. DOI:10.15826 / analitika.2018.22.4.002
Лабусов В.А., Болдова С.С., Селюнин Д. 0., Скоробогатов Д.Н., Саушкин М.С., Зарубин И.А., Бокк Д. Н., Семёнов 3. В., Неклюдов О.А., Ващенко П. В. Атомно-абсорбционный спектрометр высокого разрешения для одновременного многоэлементного анализа. DOI:10.15826 / analitika.2018.22.4.003 